\title{
Sistem Pemantauan dan Pengendali Pendingin Ruangan Cerdas Berbasis Cloud dengan Raspberry PI
}

\author{
Rahmi Khalidah dan Nanta Fakih Prebianto* \\ Teknik Elektro, Politeknik Negeri Batam, Batam, Indonesia \\ *Email: nanta@polibatam.ac.id
}

\begin{abstract}
Abstrak- Saat ini telah banyak dikembangkan sistem monitoring dan controlling pendingin ruangan berbasis Internet of Things (IoT). IoT dalam hal ini digunakan untuk mentranformasikan data suhu ruangan melalui internet sehingga data suhu yang ditampilkan merupakan data terbaru yang bersifat real time. Sistem yang dibuat dalam penelitian ini menggunakan sensor DHT22 sebagai sensor suhu dan kelembapan, dan sensor Infrared (IR) sebagai pengirim sinyal IR ke pendingin ruangan. Hasil akhir berupa monitoring suhu dan kelembapan ruangan serta controlling suhu pendingin ruangan ditampilkan pada aplikasi smartphone dan dapat dikendalikan. Monitoring dan controlling dapat dilakukan jarak jauh melalui smartphone.
\end{abstract}

Kata kunci: Internet of Things, sensor suhu, sensor infrared, aplikasi smartphone.

\section{PENDAhUluan}

DALAM kehidupan sehari hari, Internet of Things (IoT) sangat berguna dan sudah mulai banyak digunakan, termasuk untuk melakukan monitoring dan mengontrol suhu ruangan melalui jaringan internet. Dengan adanya sistem ini, maka kita dapat dengan mudah untuk memantau pendingin ruangan yang ada di rumah atau di kantor yang akan digunakan.

Tujuan dari penelitian ini adalah membuat sebuah sistem pemantau dan pengendali pendingin ruangan, yang ditempatkan di dalam ruangan, untuk mempermudah monitoring dan mengendalikan pendingin ruangan dari jarak jauh. Aplikasi yang akan penulis rancang mempunyai beberapa manfaat, baik dari segi efisiensi maupun efektivitas. Kegiatan monitoring dan pengendali pendingin ruangan dapat dilakukan di mana saja. Suhu yang ditampilkan merupakan suhu aktual. Sistem ini sudah dapat langsung mengirim data yang diterima secara real time.

\section{TINJAUAN PUSTAKA}

IoT adalah sebuah konsep di mana suatu perangkat dapat memiliki kemampuan untuk mentransfer data melalui jaringan internet tanpa melalui aktivitas fisik antara masing-masing perangkat [1], [2].

\section{METODE}

Penelitian ini menggunakan Node-RED, yakni sebuah perangkat lunak pemrograman yang digunakan untuk menghubungkan komponen eletronik seperti sensor dan mikrokontroller secara online, node-RED menyediakan editorberbasis browser sehingga memudahkan untuk mengghubungkan antar sensor [3].

Platform yang digunakan adalah Blynk, yaitu sebuah Platform IoT yang menghubungkan antara perangkat smartphone ke cloud, merancang aplikasi untuk memantau dan mengendalikan sensor dari jarak jauh [3].

Pada penelitian ini, penulis menggunakan LED IR Transmitter yang berfungsi sebagai pengirim sinyal inframerah ke pendingin ruangan. Sinyal yang dikirim berisikan perintah untuk mengendalikan pendingin ruangan. Sensor DHT22 digunakan untuk membaca suhu dan kelembapan yang digunakan untuk mendeteksi suhu dan kelembaban udara. Sensor DHT22 merupakan sensor pengukur suhu dan kelembaban relatif dengan keluaran berupa sinyal digital.

Raspberry Pi 3 digunakan dalam penelitian ini sebagai controller. Rasberry Pi Disebut juga sebagai mini PC karena memiliki spesifikasi yang cukup untuk melakukan task atau pekerjaan ringan pada PC umumnya. Raspberry sering digunakan sebagai controller mini dalam beberapa proyek berbasis IoT. Raspberry Pi 3 memiliki 40 pin GPIO, 4 port USB 2.0, sebuah port analog video-audio,sebuah Camera Serial Interface (CSI), dan penyimpanan microSD.

\section{A. Perangkat Keras}

Alur data dimulai dari pengiriman data awal dari sensor DHT22 ke Raspberry. Data yang dikirimkan sensor DHT22 berupa pembacaan suhu dan kelembapan pada ruangan berpendingin. Data ditampilkan di aplikasi yang diakses oleh user melalui smartphone. Setelah itu, user memberikan input berupa perintah yang di kirimkan kembali ke Raspberry dan Raspberry akan mengirimkan sinyal perintah ke pendingin ruangan melalui LED IR. Alur ini dijelaskan pada Gambar 1. 


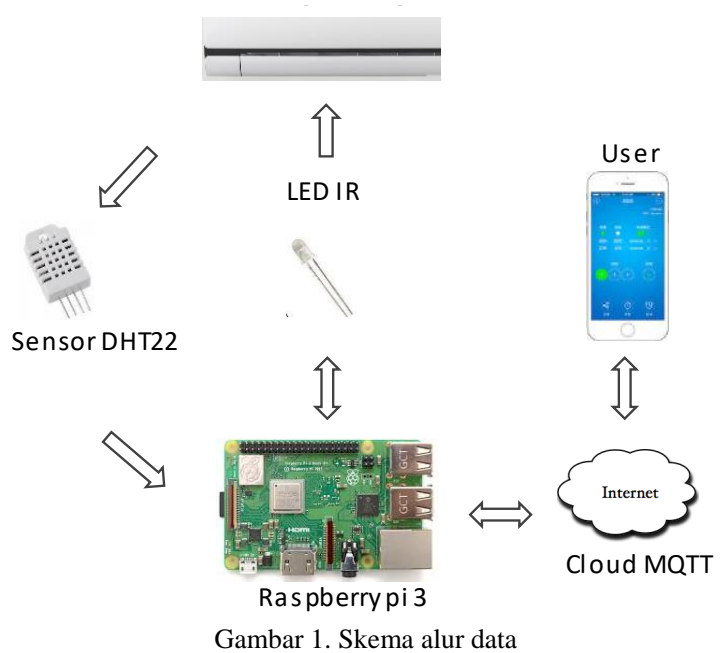

Modul diletakkan di dalam ruangan. Agar efisien dan rapi, rangkaian mikrokontroller dan sensor di letakan di dalam kotak hitam. Desain rangkaian sensor dan Rapberry menggunakan oerangkat lunak Fritzing. Lihat Gambar 2.

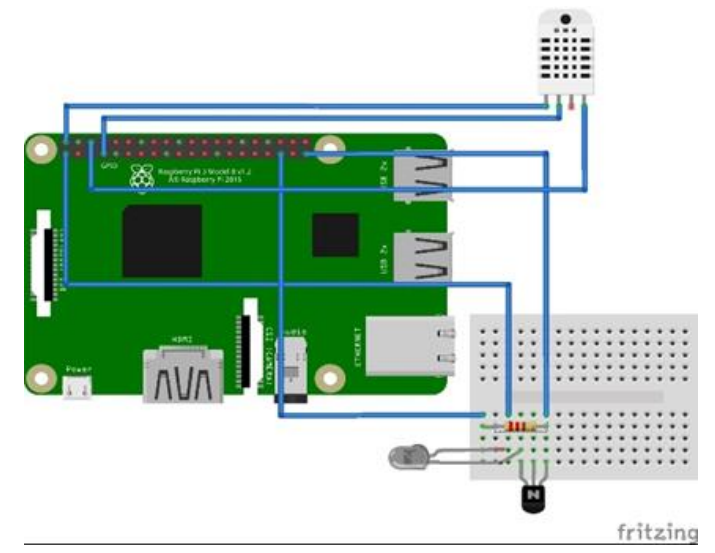

Gambar 3. Desain rangkaian

\section{B. Perangkat Lunak}

Flowchart dari cara kerja sistem yang dibuat dapat dilihat pada Gambar 3. Raspberry akan melakukan proses pairing yaitu menyambungkan Raspberry ke koneksi internet yang sudah didaftarkan. Kemudian jika koneksi berhasil, sensor DHT22 akan mengirikan data pembacaan suhu dan kelembapan ke Raspberry. Selanjutnya, Raspberry mengirimkan data, kemudian data ditampilkan di aplikasi monitoring. Jika data monitoring sudah ditampilkan pada aplikasi, selanjutnya user dapat melakukan perintah tertentu dari aplikasi. Jika perintah berhasil dieksekusi, maka proses selesai.

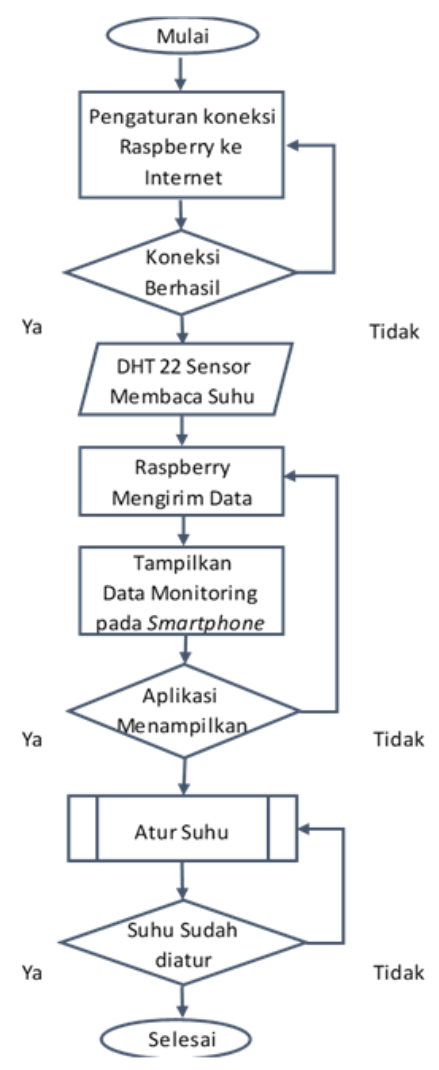

Gambar 2. Flowchart cara kerja sistem

\section{Desain Node-RED}

Gambar 3 menunjukkan desain alur sistem yang menghubungkan sensor-sensor pada Node-RED.

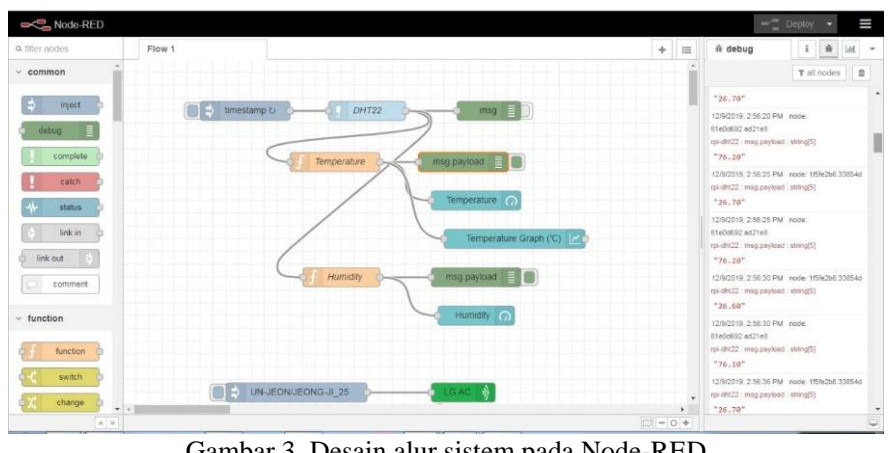

\section{Pengujian Sensor}

Pengujian sensor suhu dan kelembapan dilakukan di kampus Politeknik Negeri Batam ruang TF 1.4, di mana pendingin ruangan yang digunakan adalah pendingin ruangan tipe split SN12LFG merek LG (model HSNC126B4A1). Pengujian awal adalah pembacaan dan pengiriman suhu dari sensor DHT22 ke Raspberry yang bertujuan untuk mengetahui apakah sensor DHT22 berfungsi dengan baik. Sensor diletakkan tidak jauh dari pendingin ruangan. Selain menggunakan DHT22, pengukuran kelembapan dilakukan juga dengan menggunakan thermo hygrometer HTC-1 untuk perbandingan.

Pengujian sensor infrared bertujuan untuk mengetahui apakah sensor infrared mengirimkan data sinyal pada 
pendingin ruangan. Pengujian ini juga bertujuan untuk mengetahui jarak maksimal sensor infrared dapat diterima oleh pendingin ruangan. Sebelum melakukan pengujian pada sensor infrared, dilakukan inisialisasi terlebih dahulu pada remote infrared pendingin ruangan pada Raspberry. Ini dimaksudkan agar ketika mengirim sinyal, pendingin ruangan dapat membaca sinyal yang dikirim. Selain inisialisasi, juga dimasukkan coding berupa perintah-perintah yang akan dikirimkan seperti menghidupkan, mematikan, menaikkan, dan menurunkan suhu pendingin ruangan.

\section{HASIL DAN PEMBAHASAN}

\section{A. Monitoring Suhu}

Data dari sensor DHT22 dikirim ke Raspberry. Data tersebut kemudian ditampilkan pada user interface (Gambar 4). Gambar tersebut menunjukan suhu ruangan yang terbaca oleh sensor DHT22, yakni $26.7^{\circ} \mathrm{C}$, dengan kelembapan ruangan $76.5 \% \mathrm{RH}$.

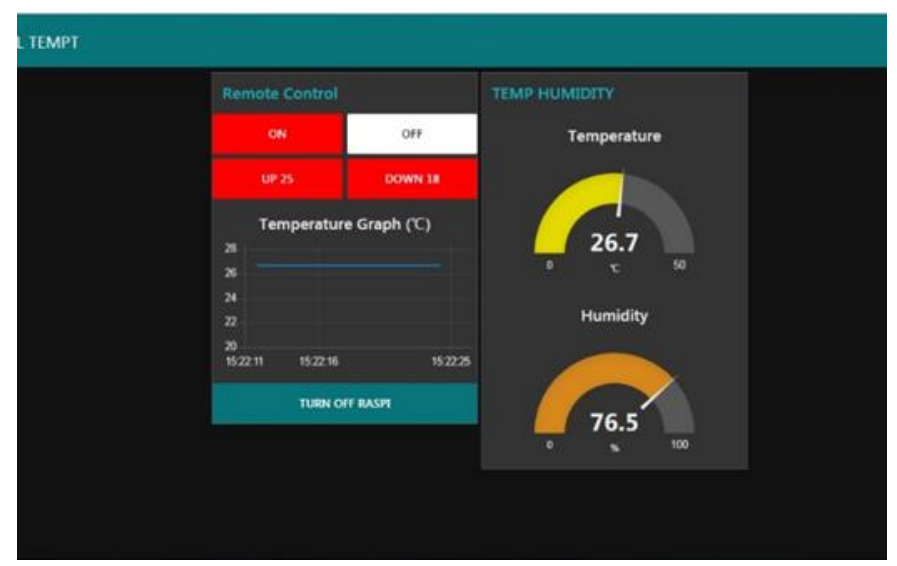

Gambar 4. User interface menampilkan data suhu dari sensor DHT22

Perbandingan hasil pembacaan sensor DHT dan HTC-1 ditunjukkan pada Gambar 5. Di sebelah kiri terlihat pembacaan suhu ruangan oleh sensor thermo hygrometer HTC-1, sedangkan di sebelah kanan terlihat pembacaan suhu ruangan oleh sensor DHT22. Data diakses melalui smartphone. Pengambilan sampel dilakukan dengan selang waktu 1 menit. Perbandingan pembacaan suhu pada sensor ruangan HTC-1 dan sensor DHT22, dapat dilihat pada Tabel I.

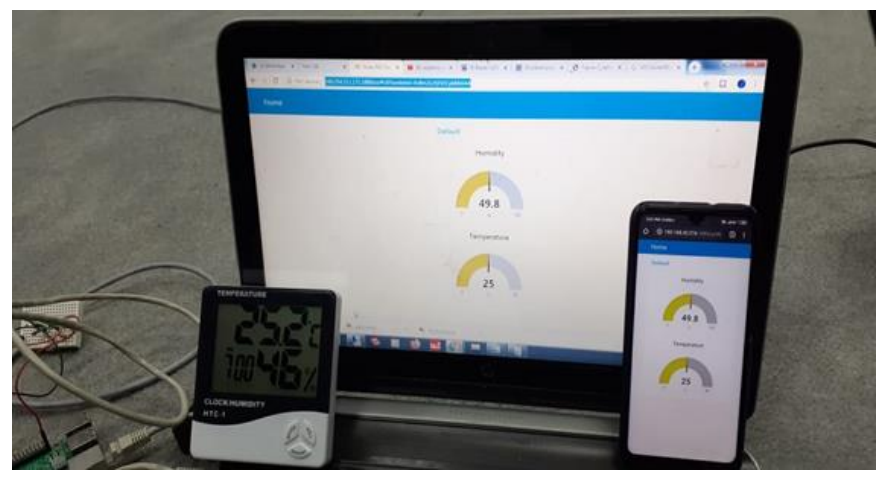

Gambar 5. Pembacan suhu ruangan antara sensor DHT22 dan sensor HTC-1
TABEL I

PERBANDINGAN PEMBACAAN SUHU PADA SENSOR HTC-1 DAN DHT22

\begin{tabular}{|c|c|c|}
\hline $\begin{array}{c}\text { Sensor } \\
\text { DHT 22 } \\
\left({ }^{\circ} \mathbf{C}\right)\end{array}$ & $\begin{array}{c}\text { Sensor } \\
\text { HTC-1 }\left({ }^{\circ} \mathbf{C}\right)\end{array}$ & Selisih \\
\hline 24,7 & 24,9 & 0,2 \\
\hline 24,8 & 25 & 0,2 \\
\hline 25 & 25,2 & 0,2 \\
\hline 25 & 25,5 & 0,5 \\
\hline 25,1 & 25,7 & 0,6 \\
\hline 25,3 & 25,8 & 0,5 \\
\hline 25,3 & 26 & 0,7 \\
\hline 25,3 & 26 & 0,7 \\
\hline 25,3 & 26 & 0,7 \\
\hline 25,3 & 26,1 & 0,8 \\
\hline
\end{tabular}

Berdasarkan Tabel I, dapat dilihat rata-rata pembacaan suhu sensor DHT22 yaitu $24,7 \sim 25,3^{\circ} \mathrm{C}$ dan rata-rata pembacaan suhu sensor HTC-1 24,9 26, $1^{\circ} \mathrm{C}$. Pembacaan sensor memiliki selisih 0,2 0,8. Rata-rata selisih pembacaan sensor adalah 0,51 .

\section{B. Kendali Suhu}

Sebelum dilakukan pengiriman perintah, user terlebih dahulu harus membuka aplikasinya secara online. Tampilan akhir monitoring dan controlling pada aplikasi Blynk dapat dilihat pada Gambar 6. Untuk controlling pada aplikasi Blynk, terdapat beberapa tombol untuk mengatur pendingin ruangan. Keterangan tombol dan fungsinya dapat dilihat pada Tabel II.

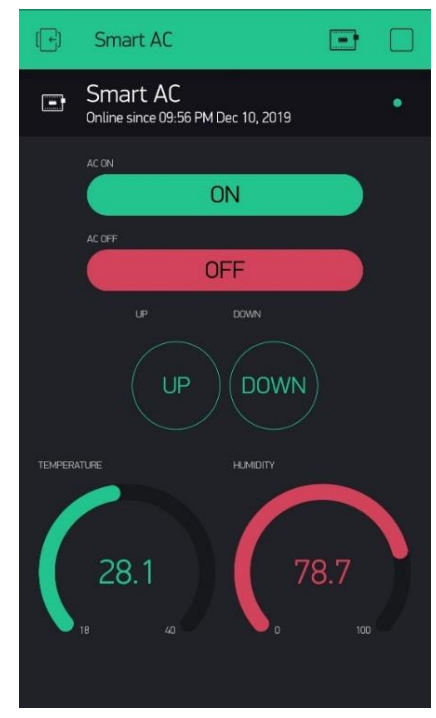

Gambar 6, Tampilan pada aplikasi Blynk

TABEL II

KETERANGAN FUNGSI TOMBOL

\begin{tabular}{|l|l|}
\hline \multicolumn{1}{|c|}{ Nama Tombol } & \multicolumn{1}{c|}{ Keterangan } \\
\hline Tombol ON & Menghidupkan AC \\
\hline Tombol OFF & Mematikan AC \\
\hline Tombol UP & Menaikan suhu AC \\
\hline Tombol DOWN & Menurunkan suhu AC \\
\hline
\end{tabular}

\section{Pengujian Sensor Infrared}

Pengujian sensor infrared dilakukan di dalam ruangan. Pengujian bertujuan untuk mengetahui jarak maksimal sinyal sensor infrared dapat diterima oleh pendingin ruangan. Hasil pengujian ditunjukkan pada Tabel III. 
TABEL III

PENGUJIAN JARAK SENSOR INFRARED

\begin{tabular}{|c|l|}
\hline Jarak sensor terhadap AC $(\mathrm{cm})$ & \multicolumn{1}{|c|}{ Keterangan } \\
\hline 15 & Sinyal terbaca \\
\hline 20 & Sinyal terbaca \\
\hline 40 & Sinyal terbaca \\
\hline 60 & Sinyal terbaca \\
\hline 80 & Sinyal terbaca \\
\hline 100 & Sinyal terbaca \\
\hline 120 & Sinyal terbaca \\
\hline 140 & Sinyal terbaca \\
\hline 160 & Sinyal terbaca \\
\hline 180 & Sinyal terbaca \\
\hline 200 & Sinyal terbaca \\
\hline 210 & Sinyal terbaca \\
\hline 215 & Sinyal tidak terbaca \\
\hline
\end{tabular}

Berdasarkan data pada Tabel III, peletakan alat yang paling efisien adalah pada jarak $50 \mathrm{~cm}$ dari bawah pendingin ruangan karena jika penempatan terlalu dekat dengan pendingin ruangan maka yang terbaca oleh sensor DHT22 adalah suhu keluaran pendingin ruangan. Jika peletakan alat terlalu jauh dari pendingin ruangan, maka sinyal infrared tidak dapat dibaca oleh pendingin ruangan. Jarak pembacaan sensor infrared oleh pendingin ruangan maksimal pada jarak $210 \mathrm{~cm}$

Untuk pengujian derajat, peletakan sensor infrared dilakukan di dalam ruangan. Pengujian bertujuan untuk mengetahui jarak maksimal sinyal sensor infrared dapat diterima oleh pendingin ruangan. Hasil pengujian dapat dilihat pada Tabel IV.

TABEL IV

PENGUJIAN DERAJAT PELETAKAN SENSOR INFRARED

\begin{tabular}{|c|l|}
\hline Derajat peletakan sensor & \multicolumn{1}{c|}{ Keterangan } \\
\hline $0^{\circ}$ & Sinyal terbaca \\
\hline $45^{\circ}$ & Sinyal terbaca \\
\hline $90^{\circ}$ & Sinyal terbaca \\
\hline $135^{\circ}$ & Sinyal terbaca \\
\hline $180^{\circ}$ & Sinyal terbaca \\
\hline $225^{\circ}$ & Sinyal tidak terbaca \\
\hline $270^{\circ}$ & Sinyal tidak terbaca \\
\hline $315^{\circ}$ & Sinyal tidak terbaca \\
\hline $360^{\circ}$ & Sinyal tidak terbaca \\
\hline
\end{tabular}

Berdasarkan Tabel IV, derajat peletakan alat yang paling efisien adalah pada kemiringan $90^{\circ}$ dari bawah pendingin ruangan (Infrared sejajar lurus dibawah pendingin ruangan). Dengan demikian, sinyal infrared dapat dibaca oleh pendingin ruangan. Setelah kemiringan $180^{\circ}$, sinyal infrared tidak terbaca.

Pengujian berikutnya adalah menguji berapa lama durasi suhu ruangan mencapai suhu yang di keluarkan oleh pendingin ruangan (set point). Pengujian dilakukan pada ruangan VR pada gedung teaching factory polibatam. Hasil pengujian dapat dilihat pada Gambar 7. Berdasarkan data pada Gambar 7, diketahui bahwa total waktu suhu ruangan mencapai set point adalah 26 menit. Ketika pada menit 26 (yaitu pukul 20:58) suhu ruangan mencapai 25 derajat celcius. Grafik tersebut menunjukkan bahwa untuk mencapai suhu set point, membutuhkan waktu selama 26 menit.

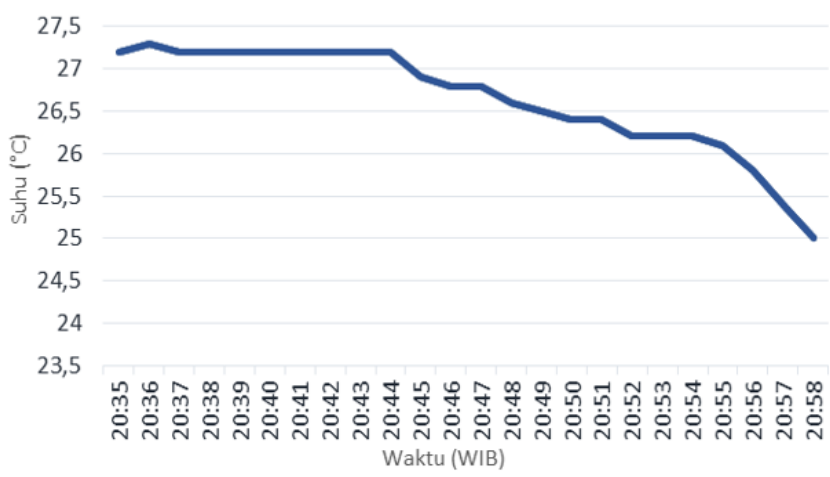

Gambar 7. Grafik lama waktu suhu ruangan mencapai set point

\section{Kesimpulan}

Untuk melakukan pemantauan dan pengendalian suhu dan kelembapan, user harus dalam posisi online. Proses pengiriman dan penerimaan data dipengaruhi kondisi kecepatan dan kestabilan jaringan internet yang diakses user. Berdasarkan hasil pengujian, jarak pembacaan sensor infrared oleh pendingin ruangan maksimal pada jarak $210 \mathrm{~cm}$. Peletakan sensor infrared dapat terbaca adalah 180 derajat terletak dari pendingin ruangan. Lama waktu yang diperlukan agar suhu ruangan mencapai suhu set point adalah 26 menit.

\section{REFERENSI}

[1] M. P. T. Sulistyanto, D. A. Nugraha, N. Sari, N. Karima, and W. Asrori, "Implementasi IoT (IoTs) dalam pembelajaran di Universitas Kanjuruhan Malang," SMARTICS J., vol. 1, no. 1, pp. 20-23, Nov. 2015.

[2] D. Prihatmoko, "Penerapan IoTs (IoT) Dalam Pembelajaran di Unisnu Jepara," Simetris J. Tek. Mesin, Elektro dan Ilmu Komput., vol. 7, no. 2, p. 567, Nov. 2016.

[3] S. Mulyono, M. Qomaruddin, and M. S. Anwar, "Penggunaan Node-RED pada Sistem Monitoring dan Kontrol Green House berbasis Protokol MQTT," TRANSISTOR Elektro dan Inform., vol. 3, no. 1, pp. 31-44, May 2018. 